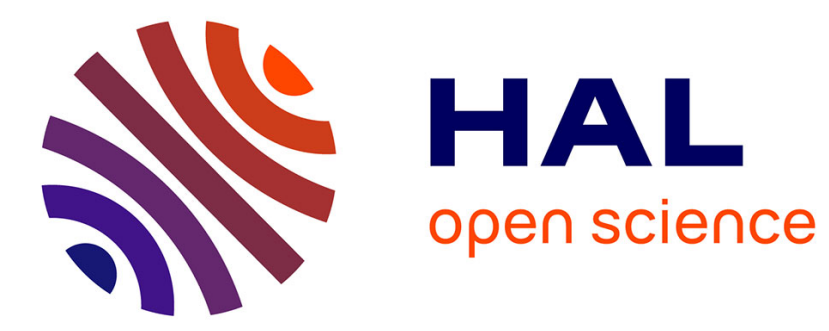

\title{
Chromosomal aberrations in iris melanomas
}

Hanneke Mensink, Jolanda Vaarwater, Rob J.W. de Keizer, Didi de

Wolff-Rouendaal, Neeltje Mooy, Annelies de Klein, Dion Paridaens

\section{To cite this version:}

Hanneke Mensink, Jolanda Vaarwater, Rob J.W. de Keizer, Didi de Wolff-Rouendaal, Neeltje Mooy, et al.. Chromosomal aberrations in iris melanomas. British Journal of Ophthalmology, 2010, 95 (3), pp.424. 10.1136/bjo.2010.181289 . hal-00580681

\section{HAL Id: hal-00580681 \\ https://hal.science/hal-00580681}

Submitted on 29 Mar 2011

HAL is a multi-disciplinary open access archive for the deposit and dissemination of scientific research documents, whether they are published or not. The documents may come from teaching and research institutions in France or abroad, or from public or private research centers.
L'archive ouverte pluridisciplinaire HAL, est destinée au dépôt et à la diffusion de documents scientifiques de niveau recherche, publiés ou non, émanant des établissements d'enseignement et de recherche français ou étrangers, des laboratoires publics ou privés. 


\section{Chromosomal aberrations in iris melanomas}

H.W. Mensink ${ }^{1,2}$, J. Vaarwater ${ }^{1,3}$, R.J.W. de Keizer ${ }^{4}$, D. de Wolff-Rouendaal ${ }^{4}$, C.M. Mooy $^{5}$, A. de Klein ${ }^{2}$ and D. Paridaens ${ }^{1}$

Author's Affiliations: ${ }^{1}$ Department of Ocular Oncology, the Rotterdam Eye Hospital, Departments of ${ }^{2}$ Clinical Genetics, ${ }^{3}$ Ophthalmology and ${ }^{5}$ Pathology, Erasmus Medical Center Rotterdam, and the Department of ${ }^{4}$ Ophthalmology, Leiden University Medical Center, The Netherlands

Grant Support: SWOO-Flieringa Foundation and Professor Henkes Foundation Competing Interest: None declared.

Corresponding author:

H.W. Mensink, Department of Ocular Oncology, The Rotterdam Eye Hospital, PO Box 70030, 3000 LM Rotterdam, The Netherlands

Requests for reprints: h.mensink@oogziekenhuis.nl 


\begin{abstract}
Background. Uveal melanomas can develop in the choroid, ciliary body and in the iris. In choroidal and ciliary body melanomas specific chromosomal changes correlate with metastatic disease. Iris melanomas have a better prognosis than choroidal melanomas and it would be interesting to know if they share chromosomal changes. In addition, iris melanomas might harbour UV-induced mutations of tumour suppressor genes, such as PTEN and CDKN2A.

Methods. Twenty iris melanomas were analyzed for chromosome 1p, 3, 6, 8, 9p and 10q abnormalities using fluorescence in situ hybridization. These results were correlated to clinical follow-up data using statistical analyses.

Results. (Partial) loss of chromosome 3 was observed in 9 iris melanomas and gain of $8 \mathrm{q}$ was present in 7 tumours. Loss of chromosome 9p was demonstrated in 7 tumours but no deletions of the PTEN region on chromosome 10 were found. Three patients died of metastatic disease and one patient developed liver metastases, but is still alive. Univariate analysis indicated a lower disease free survival for patients with diffuse growing melanomas $(\mathrm{p}=0.01)$, melanomas that lost a copy of chromosome $3(\mathrm{p}=0.03)$, or invading the ciliary body $(\mathrm{p}=0.01)$. In multivariate analysis none of the correlations were significant.
\end{abstract}

Conclusion. Loss of chromosome 3 as well as loss of chromosomal region 9p21 (that entails tumour suppressor gene CDKN2A) play a role in iris melanoma. A firm correlation with disease-free survival could not be established, possibly due to the small sample size,

Key words: iris melanoma, FISH, monosomy 3, CDKN2A 


\section{Introduction}

Iris melanomas are the least common of uveal melanomas $(<6 \%)$ and tend to present at a smaller size than posterior melanomas. ${ }^{1}$ They can cause drainage blockage of the anterior chamber angle and secondary elevation of the intraocular pressure. They carry a better prognosis compared to other uveal melanomas with a metastatic rate of $0.5 \%$ at 3 and $7 \%$ at 10 years, respectively. ${ }^{2}$ Melanocytic lesions of the iris are usually managed by a 'wait and see policy' with regular follow-ups to detect possible growth. Biomicroscopy, gonioscopy and measurements with the slit lamp are standard tests. Ancillary tests such

as fluorescein angiography and ultrasound biomicroscopy are sometimes needed to assess growth more accurately. Iris melanomas can be treated by local excision, enucleation or radiotherapy. Metastases are more likely to develop in those patients who are older or with diffuse iris melanomas, compared to well-defined nodular ones. Other warning signs are tumour features of iris root location and ciliary body invasion with elevated intraocular pressure and extraocular extension. ${ }^{3}$ The differential diagnosis of iris melanoma includes Cogan Reese syndrome, nevus, melanocytoma, metastasis, adenoma, adenocarcinoma, cysts and pigment dispersion syndrome. ${ }^{4}$

The favourable outcome of iris melanomas compared to choroidal and ciliary body melanomas is poorly understood. To determine the prognosis on only histological classification proved to be difficult. ${ }^{5}$ Therefore, more accurate tests are needed. The different anatomical locations of the intraocular melanomas result in different microenvironments. Aqueous humour and vitreous contain various soluble factors that might influence cell growth. ${ }^{6}$ Another differential factor is UV-radiation. Its role in uveal melanoma is inconclusive, but arguably the iris is more exposed to the sun than the choroid. ${ }^{7-13}$ While UV-radiation might induce changes in the genome, intrinsic genetic differences may also play a role. ${ }^{14}$

To further elucidate the genetic differences between choroidal and iris melanomas, the following study was performed. Twenty iris melanomas were analyzed for chromosomal aberrations well known in choroidal and ciliary body melanomas, such as loss of 
chromosome 3 and gain of chromosome $8 q^{15}$, in addition to common changes in skin melanomas, such as loss of 9p21 and 10q23 (regions that harbour the tumour suppressor genes CDKN2A and PTEN, respectively). ${ }^{16}$

\section{Materials and methods}

The research methodology followed the tenets of the Declaration of Helsinki. Informed consent was obtained for the use of human tissue from the patients. The research was approved by the local research ethics committee. All cases of iris melanomas were collected from the files from the departments of pathology in Rotterdam (1993-2009) and Leiden (1980 to 2009) and reviewed retrospectively. Cases that originated from the ciliary body were excluded as well as patients who had no available follow-up information. This resulted in 22 iris melanomas available for our study. FISH (Fluorescence in situ Hybridisation) was unsuccessful in 2 cases.

The enucleation and biopsy specimens were fixed in standard 10\%, buffered formalin for $24 \mathrm{~h}$. They were embedded in conventional, paraffin wax and sections were cut at $5 \mu \mathrm{m}$. Sections were stained with Haematoxylin and Eosin $(\mathrm{H} \& \mathrm{E})$ in order to obtain a histopathological diagnosis. The specimens were reviewed and classified according to the Jakobiec histopathologic classification of iris melanocytic tumours ${ }^{5}$ : group 1 melanocytosis, group 2 melanocytoma, group 3 epithelioid cell nevus, group 4 intrastromal spindle cell nevus, group 5 spindle cell nevus with surface plaque, group 6 borderline spindle cell nevus, group 7 spindle cell melanoma, group 8 mixed spindle and epithelioid cell melanoma, group 9 epithelioid cell melanoma.

Paraffin-embedded iris melanoma slides were used for FISH (chromosome 1p, 3, 6, 8, 9p and 10q). The pathologist located the tumour and dual colour FISH (digoxygenin and biotin labelled probes) was performed with the following probes: RP11-48E9 (1p36), RP11-522N9 (3p13), Pa3.5 (centromere 3), RP11-64F6 (3q25), RP11-356B3 (6p22), 
RP11-787I22 (6q21), RP11-24P4 (8p21), D8Z2 (centromere 8), RP11-88J22 (8q22), P1.063 (9p21) and PAC190D6 (10q23). ${ }^{17}$ The concentration for centromeric probes was $5 \mathrm{ng}$ per slide and for BAC probes 50 to $75 \mathrm{ng}$ per slide was used. As a control for aneuploidy a probe on chromosome 5 was used: RP11-1059N10 (5q12). The tissue sections were pretreated by dewaxing with xylene, permeabilizing with sodium thyocyanate, proteolysis and denaturation. After hybridization and washing, slides were counterstained with 4', 6-diamidino-2-phenylindole and mounted in anti-fade solution (Dabco-Vectashield 1:1). The amount of scored nuclei depended on the size of the tumour, at least 50 nuclei and till a maximum of 200 nuclei were scored. Cut-off limits for deletion ( $>25 \%$ of the nuclei with one signal) or amplification $(>10 \%$ of the nuclei with 3 or more signals) were adapted from own experiments and the available literature. ${ }^{18}$

The primary endpoint for disease free survival (DFS) was the time to development of metastatic disease, whereby death due to other causes was being censored. Statistical analyses were performed with SPSS software, release 15.0. Actuarial probabilities of disease free survival (with an event defined as development of metastatic disease or metastasis-related death) were estimated according to the Kaplan-Meier method. To examine the possibility that other clinical, histopathological or chromosomal variations affected the prognosis, we performed Cox proportional hazard analysis for each confounding variable. An effect was considered significant if the p-value was 0.05 or less. The following factors were evaluated: age, cell type (spindle, mixed or epithelioid cell), Jakobiec classification, growth pattern (nodular, multiple nodules or diffuse), involvement of ciliary body, tumour invasion of the chamber angle, chromosomal aberrations (chromosomes 1, 3, 6p, 6q, 8q, 9p and 10q). 


\section{Results}

Tumour characteristics

Twenty iris melanomas were included in our study. The specimens were classified

according to the Jakobiec histopathologic classification of iris melanocytic tumours ${ }^{5}: 3$ borderline spindle cell nevi, 4 spindle cell melanomas, 6 mixed spindle and epithelioid cell melanomas and 7 epithelioid cell melanomas (Figure 1).

Fifteen melanomas grew in the chamber angle resulting in secondary glaucoma in 5 cases caused by angle closure. Nine iris melanomas that spread into the angle also spread into the ciliary body, but primarily originated from the iris and in all of them epithelioid cells were present (Table 1).

\section{Clinical data}

The median age of the patients at the time of diagnosis was 62 years. Three patients had a trabeculectomy for glaucoma in their medical history (melanoma \# 2, 9 and 14). Surgery or Ruthenium plaque irradiation was chosen to treat the iris melanoma.

The median follow-up time was 42 months (range 2-204 months). Three patients died of metastases. One patient had been treated with a trabeculectomy 12 years earlier (histopathological diagnosis at that time: Cogan Reese syndrome) and died of metastatic disease (melanoma \# 9). The second patient presented with metastases, located in the bones and submandibular lymph nodes, 3 years after a trabeculectomy (histopathological diagnosis at that time: iris nevus without signs of malignancy) (melanoma \#1). The third patient died of liver metastases 3 years after the iris melanoma, treated by Ruthenium plaque irradiation, recurred. This recurrence was treated by enucleation (melanoma \#13). Another patient presented with liver metastases 2,3 years after enucleation as the primary treatment of her iris melanoma (melanoma \#10).

FISH results

All 20 iris melanoma tissue slides could be hybridized with the chromosome $3 p$ and centromere 3 probe. For the other FISH probes it was not always possible to obtain data, 
because often the material was too sparse to give a definite answer. See table 2 for the results.

FISH Analysis of paraffin sections demonstrated (partial) loss of chromosome 3 in nine tumours. Seven melanomas with loss of chromosome 3 had concomitantly gained chromosome 8q (see Figure 2). Loss of the chromosomal region 9p21 was present in seven tumours, and six of those had concomitant loss of chromosome 3 and 9p. Five tumours had all three chromosome aberrations (loss of chromosome 3, 9p and gain of 8q) mentioned above. Chromosome 10q was normal in all cases.

The tumours of the patients who died of metastases revealed loss of chromosome 3. Two of them also lost 9p21, and two melanomas had gained 8q. Two of the progressively growing melanomas were composed of mixed spindle and epithelioid cells and one was composed of epithelioid cells only. All three grew into the angle of the chamber and into the ciliary body. Three melanomas in our group were spindle cell nevi with borderline malignancy (Jakobiec group 6). Interestingly, two of them did not have any chromosomal aberrations, but the third one did lose one copy of chromosome $3 q$ and $9 p$ simultaneously with gain of chromosome 8q.

Statistical analysis

Univariate analysis was performed for all parameters, showing a lower disease free survival for patients with diffuse growing melanomas $(\mathrm{p}=0.01)$, melanomas that lost a copy of chromosome $3(\mathrm{p}=0.03)$ or invading the ciliary body $(\mathrm{p}=0.01)$. The other chromosomal aberrations did not show significant correlations. In a multivariate Cox proportional hazard analysis including growth pattern, ciliary body involvement and chromosome 3, they all lost significance. 


\section{Discussion}

Our study reports on chromosomal abnormalities in the largest group of iris melanomas described thus far. We demonstrated that in iris melanomas (partial) loss of chromosome 3 tends to occur often, in 9/20 tumours (45\%), but only correlates with progressive disease in a univariate analysis. The frequency of chromosome 3 loss is almost similar to choroidal melanomas, in which case it strongly associates with patients at risk of metastatic disease. ${ }^{19}$

Similar to common changes in skin melanomas, such as loss of 9p21 and 10q23, 7/ 20 iris melanomas $(35 \%)$ revealed loss of chromosome 9p. UV-radiation induces mutations in the $\mathrm{CDKN} 2 \mathrm{~A}$ gene that encodes for the p16 protein that acts as a negative regulator of the cell cycle and is located on chromosome $9 \mathrm{p} 21 .^{23}$ Alterations of chromosome 9 occur frequently in cutaneous melanomas and relate to progressive disease. ${ }^{24-26}$. Conversely, CDKN2A mutations are rarely observed in UM. ${ }^{20,21}$ Our results indicate a difference between iris and posterior melanomas, because loss of $9 p$ is found in 7/20 iris melanomas.

Yet, we could not demonstrate aberrations of chromosome 10q in iris melanomas. Previously, it has been reported that the tumour suppressor gene PTEN (located on chromosome 10q) is not involved in uveal melanomas, whereas mutations of PTEN are present in up to $40 \%$ of cutaneous melanomas. ${ }^{20-22}$ The same holds true for N-ras mutations. Mutations of the N-ras gene, located on chromosome 1p13, correlate with sunlight exposure and occur frequently in cutaneous melanoma arising in sun exposed areas. ${ }^{7}$ Nevertheless, N-ras mutations are usually absent in uveal melanomas, further questioning the role of sunlight in the pathogenesis of uveal melanoma. ${ }^{8,15}$ In $8 / 20$ iris melanomas the ciliary body was invaded by tumour cells, and four of these tumours spread systemically. Ciliary body involvement was only found to be a significant prognostic parameter in univariate analysis.

Little is known about somatic mutations and chromosomal aberrations in iris melanomas. To date only 8 iris melanomas have been cytogenetically analyzed and described 
worldwide. The first karyogram of an iris melanoma revealed extra copies of chromosomes 2, 7 and 18, and loss of chromosome 15. Additionally, rearrangements on chromosomes 8q, 4q, 12p and marker chromosomes were observed. ${ }^{27}$ Sisley et al. karyotyped 3 iris melanomas and did not find specific chromosomal changes common to all tumours. Clonal abnormalities of chromosomes 3, 5, 6, 7, 8, 9, 12, 15, 17, 18, 19, and $\mathrm{Y}$ were found, and in one case a large number of marker chromosomes were observed. ${ }^{14}$ They concluded that iris melanomas experience relatively high levels of chromosomal alterations compared to choroidal melanomas, which is perhaps reminiscent of cutaneous melanoma. The third study included 4 iris among other uveal melanomas that were analyzed by comparative genetic hybridization. ${ }^{28}$ Gains of chromosome $6 \mathrm{p}$ and $8 \mathrm{q}$ were identified twice and gains of chromosome $8 p$ and $13 q$ were identified once. One melanoma was completely diploid. These three studies did not identify critical chromosomal regions and, furthermore, the results were not compared to disease free survival.

In contrast, we observed involvement of chromosome $9 \mathrm{p}$ in seven tumours and loss of chromosome 3 in nine iris melanomas. These results suggest that the tumour suppressor gene CDKN2A, located on chromosome 9p, might play a role in iris melanomas, and requires analyses of the gene itself. The role of chromosome 3 loss in iris melanomas needs further investigation. The prognostic significance is not as strong as in choroidal melanomas, but possibly this is the result of the small sample size. The differences between choroidal and iris melanomas suggest that environmental influences such as UVradiation, aqueous and vitreous humour may contribute to the metastatic potential of the tumour.

\section{Acknowledgements}

The authors are grateful to L. Razzaq for helping to complete the follow-up data in Leiden. 
The Corresponding Author has the right to grant on behalf of all authors and does grant on behalf of all authors, an exclusive licence on a worldwide basis to the BMJ Publishing Group Ltd and its Licensees to permit this article (if accepted) to be published in BJO editions and any other BMJPGL products to exploit all subsidiary rights, as set out in our licence (http://group.bmj.com/products/journals/instructionsfor-authors/licence-forms). 


\section{References}

1. Henderson E, Margo CE. Iris melanoma. Arch Pathol Lab Med. 2008;132:26872.

2. Shields CL, Furuta M, Thangappan A et al. Metastasis of uveal melanoma millimeter-by-millimeter in 8033 consecutive eyes. Arch Ophthalmol. 2009;127:989-98.

3. Shields CL, Shields JA, Materin M et al. Iris melanoma: risk factors for metastasis in 169 consecutive patients. Ophthalmology. 2001;108:172-8.

4. Shields JA, Sanborn GE, Augsburger JJ. The differential diagnosis of malignant melanoma of the iris. A clinical study of 200 patients. Ophthalmology. 1983;90:716-20.

5. Jakobiec FA, Silbert G. Are most iris "melanomas' really nevi? A clinicopathologic study of 189 lesions. Arch Ophthalmol. 1981;99:2117-32.

6. Mudhar HS, Saunders E, Rundle P et al. The in vivo modulatory effects of an anterior-chamber microenvironment on uveal melanoma. Br J Ophthalmol. 2009;93:535-40.

7. Singh AD, Rennie IG, Seregard S et al. Sunlight exposure and pathogenesis of uveal melanoma. Surv Ophthalmol. 2004;49:419-28.

8. Mooy CM, Van der Helm MJ, Van der Kwast TH et al. No N-ras mutations in human uveal melanoma: the role of ultraviolet light revisited. Br J Cancer. 1991;64:411-3.

9. Schmidt-Pokrzywniak A, Jockel KH, Bornfeld N et al. Positive interaction between light iris color and ultraviolet radiation in relation to the risk of uveal melanoma: a case-control study. Ophthalmology. 2009;116:340-8.

10. Li W, Judge H, Gragoudas ES et al. Patterns of tumor initiation in choroidal melanoma. Cancer Res. 2000;60:3757-60.

11. Manning WS Jr., Greenlee PG, Norton JN. Ocular melanoma in a Long Evans rat. Contemp Top Lab Anim Sci. 2004;43:44-6.

12. Marshall JC, Gordon KD, McCauley CS et al. The effect of blue light exposure and use of intraocular lenses on human uveal melanoma cell lines. Melanoma Res. 2006;16:537-41.

13. Vajdic CM, Kricker A, Giblin M et al. Sun exposure predicts risk of ocular melanoma in Australia. Int J Cancer. 2002;101:175-82.

14. Sisley K, Brand C, Parsons MA et al. Cytogenetics of iris melanomas: disparity with other uveal tract melanomas. Cancer Genet Cytogenet. 1998;101:128-33.

15. Singh AD, Damato B, Howard P et al. Uveal melanoma: genetic aspects. Ophthalmol Clin North Am. 2005;18:85-97, viii.

16. Wu H, Goel V, Haluska FG. PTEN signaling pathways in melanoma. Oncogene. 2003;22:3113-22.

17. Naus NC, Verhoeven AC, van Drunen E et al. Detection of genetic prognostic markers in uveal melanoma biopsies using fluorescence in situ hybridization. Clin Cancer Res. 2002;8:534-9. 
18. van Dekken H, Pizzolo JG, Reuter VE et al. Cytogenetic analysis of human solid tumors by in situ hybridization with a set of 12 chromosome-specific DNA probes. Cytogenet Cell Genet. 1990;54:103-7.

19. Prescher G, Bornfeld N, Hirche $\mathrm{H}$ et al. Prognostic implications of monosomy 3 in uveal melanoma. Lancet. 1996;347:1222-5.

20. Naus NC, Zuidervaart W, Rayman N et al. Mutation analysis of the PTEN gene in uveal melanoma cell lines. Int J Cancer. 2000;87:151-3.

21. Singh AD, Croce CM, Wary KK et al. Familial uveal melanoma: absence of germline mutations involving the cyclin-dependent kinase-4 inhibitor gene (p16). Ophthalmic Genet. 1996;17:39-40.

22. Tsao H, Zhang X, Benoit E et al. Identification of PTEN/MMAC1 alterations in uncultured melanomas and melanoma cell lines. Oncogene. 1998;16:3397-402.

23. Hussein MR. Ultraviolet radiation and skin cancer: molecular mechanisms. $J$ Cutan Pathol. 2005;32:191-205.

24. Wang X, Egan KM, Gragoudas ES et al. Constitutional alterations in p16 in patients with uveal melanoma. Melanoma Res. 1996;6:405-10.

25. Hoglund M, Gisselsson D, Hansen GB et al. Dissecting karyotypic patterns in malignant melanomas: temporal clustering of losses and gains in melanoma karyotypic evolution. Int J Cancer. 2004;108:57-65.

26. Nelson MA, Radmacher MD, Simon R et al. Chromosome abnormalities in malignant melanoma: clinical significance of nonrandom chromosome abnormalities in 206 cases. Cancer Genet Cytogenet. 2000;122:101-9.

27. White VA, Horsman DE, Rootman J. Cytogenetic characterization of an iris melanoma. Cancer Genet Cytogenet. 1995;82:85-7.

28. Vajdic CM, Hutchins AM, Kricker A et al. Chromosomal gains and losses in ocular melanoma detected by comparative genomic hybridization in an Australian population-based study. Cancer Genet Cytogenet. 2003;144:12-7. 
Table 1.

\section{Table 1. Tumour characteristics}

\begin{tabular}{|c|c|c|c|c|c|c|c|c|}
\hline $\begin{array}{c}\text { Iris melanoma } \\
\text { no\# }\end{array}$ & $\begin{array}{c}\text { Age } \\
\text { years }\end{array}$ & $\begin{array}{l}\text { Jakobiec } \\
\text { group }\end{array}$ & $\begin{array}{l}\text { Growth } \\
\text { pattern }\end{array}$ & $\begin{array}{l}\text { Ciliary body } \\
\text { involved }\end{array}$ & Cell type & $\begin{array}{c}\text { Angle } \\
\text { invasion }\end{array}$ & Survival & Metastases \\
\hline 1 & 53 & 9 & diffuse & yes & epithelioid & yes & 48 & yes $\dagger$ \\
\hline 2 & 63 & 9 & diffuse & no & epithelioid & yes & 112 & no \\
\hline 3 & 41 & 9 & multiple & yes & epithelioid & yes & 20 & no \\
\hline 4 & 55 & 9 & diffuse & yes & epithelioid & yes & 16 & no \\
\hline 5 & 77 & 6 & multiple & no & spindle & yes & 62 & no \\
\hline 6 & 76 & 6 & nodular & no & spindle & no & 10 & no \\
\hline 7 & 71 & 6 & nodular & no & spindle & no & 2 & no \\
\hline 8 & 42 & 9 & multiple & no & epithelioid & yes & 144 & no \\
\hline 9 & 52 & 8 & diffuse & yes & mixed & yes & 37 & yes $\dagger$ \\
\hline 10 & 59 & 8 & diffuse & yes & mixed & yes & 29 & yes \\
\hline 11 & 71 & 8 & diffuse & no & mixed & yes & 23 & no \\
\hline 12 & 46 & 7 & nodular & no & spindle & no & 96 & no \\
\hline 13 & 49 & 8 & nodular & no & mixed & no & 157 & no \\
\hline 14 & 62 & 7 & multiple & no & spindle & yes & 62 & no \\
\hline 15 & 69 & 9 & diffuse & no & epithelioid & yes & 5 & no \\
\hline 16 & 66 & 8 & diffuse & yes & mixed & yes & 35 & yes $\dagger$ \\
\hline 17 & 56 & 8 & multiple & yes & mixed & yes & 86 & no \\
\hline 18 & 69 & 7 & nodular & no & spindle & no & 24 & no \\
\hline 19 & 83 & 9 & multiple & yes & epithelioid & yes & 157 & no \\
\hline 20 & 67 & 7 & nodular & no & spindle & no & 204 & no \\
\hline
\end{tabular}

† Death due to metastases 
Table 2.

\begin{tabular}{|c|c|c|c|c|c|c|c|c|c|c|c|}
\hline \multirow{2}{*}{$\begin{array}{c}\text { Iris melanoma } \\
\text { no\# }\end{array}$} & \multicolumn{11}{|c|}{ Copy number per chromosomal region } \\
\hline & $1 \mathrm{p} 36$ & $3 p 13$ & cen3 & $3 q 25$ & $6 \mathrm{p} 22$ & $6 \mathrm{q} 21$ & $8 p 21$ & cen8 & $8 \mathrm{q} 22$ & $9 p 21$ & $10 \mathrm{q} 23$ \\
\hline 1 & 1 & 1 & 1 & 1 & 2 & 2 & 2 & 3 & 3 & 1 & 2 \\
\hline 2 & 2 & 1 & 1 & 1 & 2 & 1 & 3 & 3 & 3 & 1 & 2 \\
\hline 3 & 2 & 2 & 2 & 2 & 2 & 2 & 2 & 2 & 2 & 2 & 2 \\
\hline 4 & 2 & 2 & 2 & 2 & 2 & 2 & 2 & 3 & 2 & 1 & 2 \\
\hline 5 & 2 & 2 & 2 & 1 & 2 & 2 & 2 & 3 & 3 & 1 & 2 \\
\hline 6 & 2 & 2 & 2 & 2 & 2 & 2 & 2 & 2 & 2 & 2 & 2 \\
\hline 7 & 2 & 2 & 2 & 2 & 2 & 2 & 2 & 2 & 2 & 2 & 2 \\
\hline 8 & 1 & 2 & 2 & 2 & 2 & 2 & 2 & 2 & 2 & 2 & 2 \\
\hline 9 & 2 & 1 & 1 & 1 & 2 & 2 & 2 & 3 & 2 & 1 & 2 \\
\hline 10 & 2 & 1 & 1 & 1 & 2 & 2 & 1 & 3 & 3 & 2 & 2 \\
\hline 11 & 2 & 1 & 1 & 1 & 2 & 2 & 4 & 3 & 3 & 1 & 2 \\
\hline 12 & 2 & 2 & 2 & 2 & 2 & 2 & 2 & 2 & 2 & 2 & 2 \\
\hline 13 & $\mathrm{n} / \mathrm{a}$ & 2 & 2 & $\mathrm{n} / \mathrm{a}$ & $\mathrm{n} / \mathrm{a}$ & $\mathrm{n} / \mathrm{a}$ & $\mathrm{n} / \mathrm{a}$ & 3 & $\mathrm{n} / \mathrm{a}$ & $\mathrm{n} / \mathrm{a}$ & $\mathrm{n} / \mathrm{a}$ \\
\hline 14 & 1 & 1 & 1 & $\mathrm{n} / \mathrm{a}$ & $\mathrm{n} / \mathrm{a}$ & $\mathrm{n} / \mathrm{a}$ & $\mathrm{n} / \mathrm{a}$ & $\mathrm{n} / \mathrm{a}$ & 3 & 1 & 2 \\
\hline 15 & 1 & 1 & 1 & 1 & 2 & 2 & 1 & 3 & 3 & 2 & 2 \\
\hline 16 & 1 & 1 & 1 & $\mathrm{n} / \mathrm{a}$ & 2 & 1 & $\mathrm{n} / \mathrm{a}$ & $\mathrm{n} / \mathrm{a}$ & 3 & 2 & 2 \\
\hline 17 & $\mathrm{n} / \mathrm{a}$ & 2 & 2 & $\mathrm{n} / \mathrm{a}$ & $\mathrm{n} / \mathrm{a}$ & $\mathrm{n} / \mathrm{a}$ & $\mathrm{n} / \mathrm{a}$ & $\mathrm{n} / \mathrm{a}$ & $\mathrm{n} / \mathrm{a}$ & 2 & 2 \\
\hline 18 & 2 & 2 & 2 & 2 & 2 & 2 & 2 & 2 & 2 & 2 & 2 \\
\hline 19 & 1 & 1 & 1 & $\mathrm{n} / \mathrm{a}$ & $\mathrm{n} / \mathrm{a}$ & $\mathrm{n} / \mathrm{a}$ & $\mathrm{n} / \mathrm{a}$ & $\mathrm{n} / \mathrm{a}$ & 3 & 2 & 2 \\
\hline 20 & 2 & 2 & 2 & $\mathrm{n} / \mathrm{a}$ & $\mathrm{n} / \mathrm{a}$ & $\mathrm{n} / \mathrm{a}$ & $\mathrm{n} / \mathrm{a}$ & $\mathrm{n} / \mathrm{a}$ & 2 & 2 & 2 \\
\hline Total aberrations & $6 / 18$ & $9 / 20$ & $9 / 20$ & $6 / 14$ & $0 / 15$ & $2 / 15$ & $4 / 14$ & $9 / 15$ & $9 / 18$ & $7 / 19$ & $0 / 19$ \\
\hline
\end{tabular}




\section{Figure legends}

Figure 1. Histology (H\&E stain) of $\mathrm{A}$ and C) no.12, shows a spindle cell iris melanoma, and $\mathrm{B}$ and $\mathrm{D})$ no. 1, shows a epithelioid cell iris melanoma with invasion of the angle chamber .

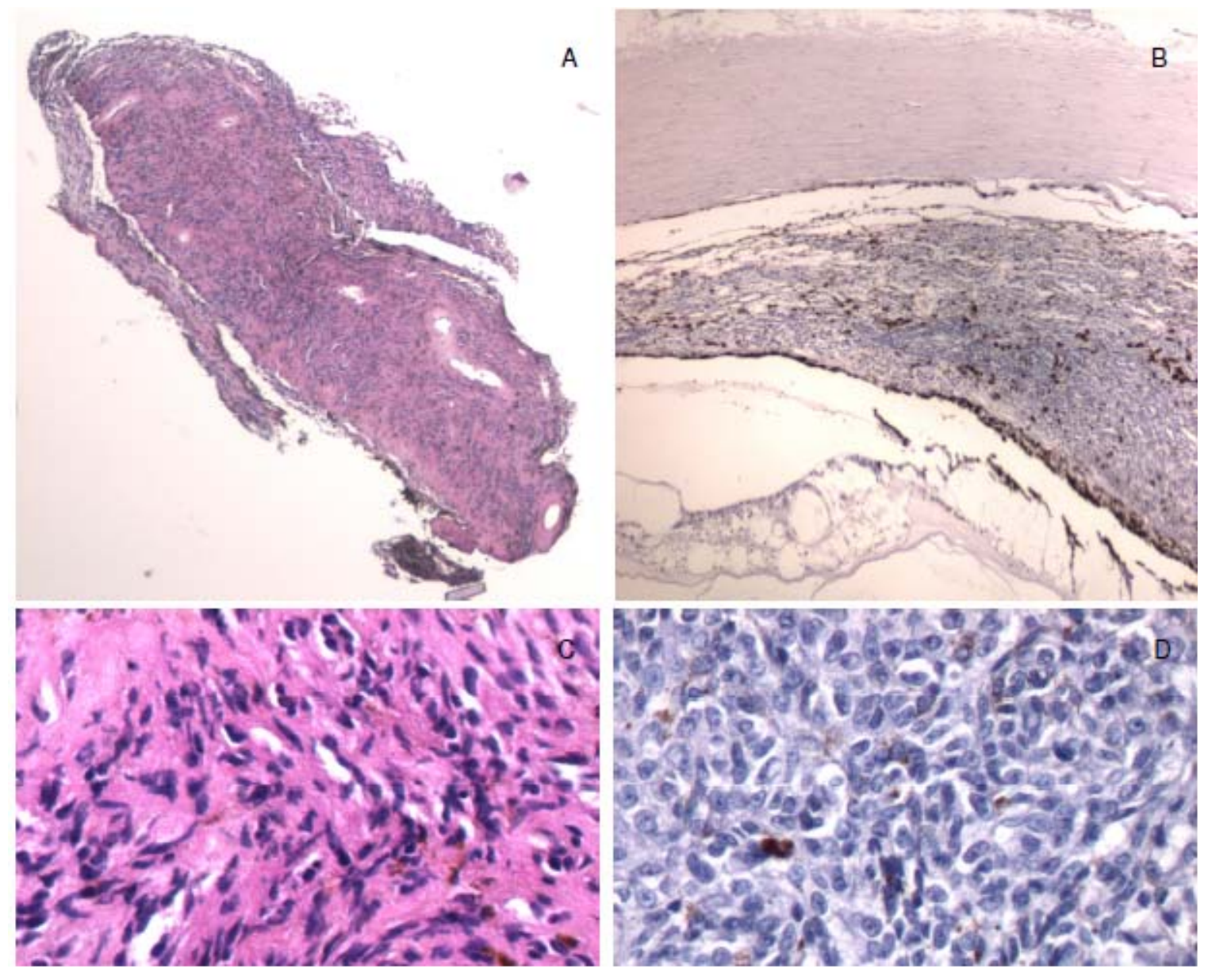


Figure 2. FISH analysis of iris melanoma no.1, EOM 149, demonstrates 2 signals for the biotin probe (red signal) on chromosome 10q and 1 signal for the digoxenin probe (green signal) on chromosome 9p (A), and 1 signal for both bio and dig probes on chromosome $3(\mathrm{~B})$.
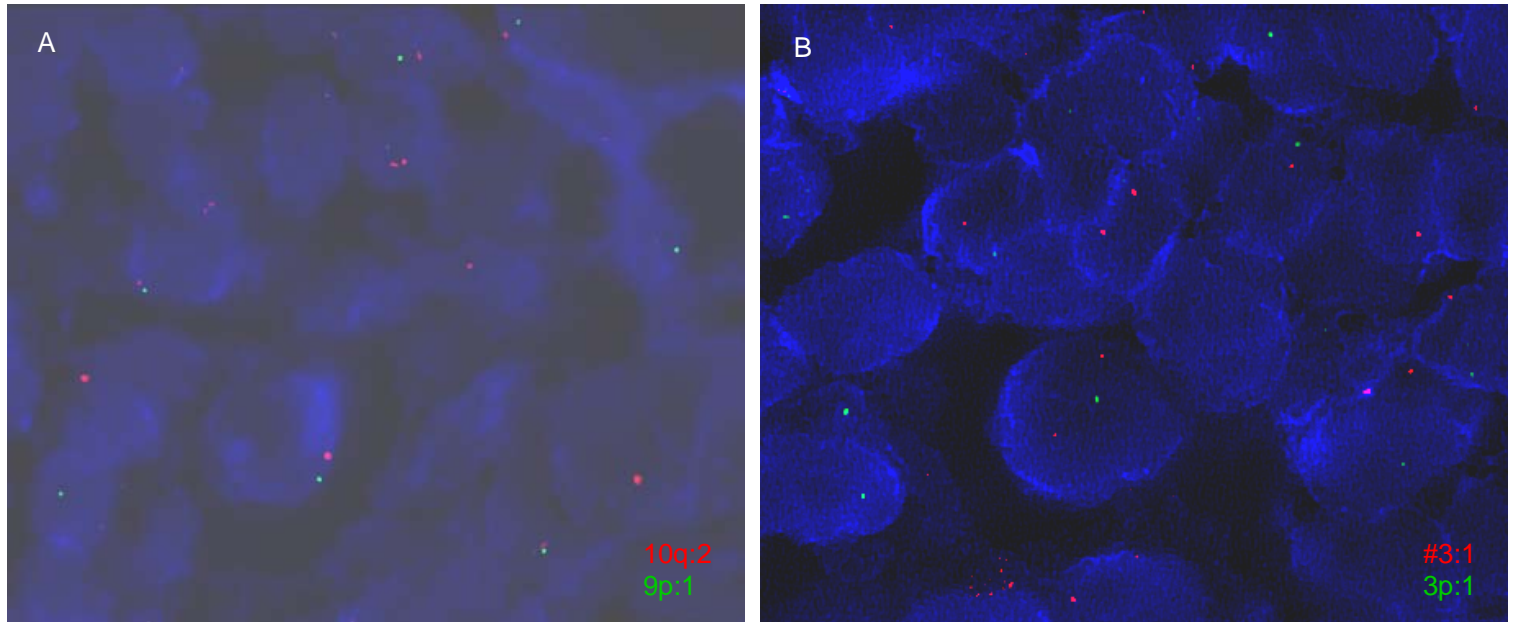

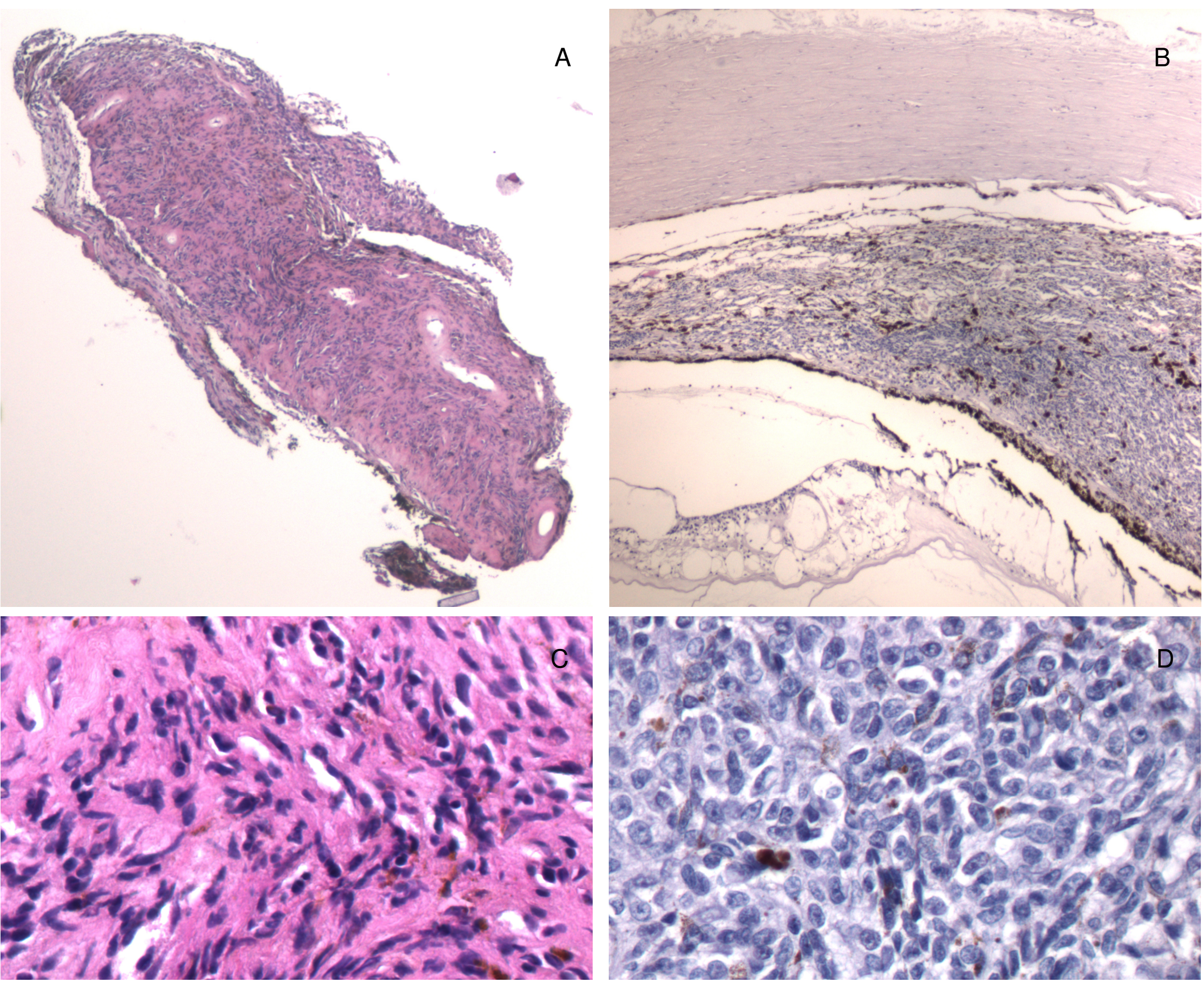

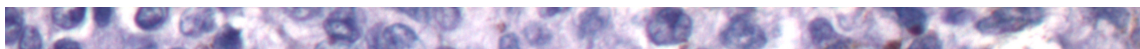

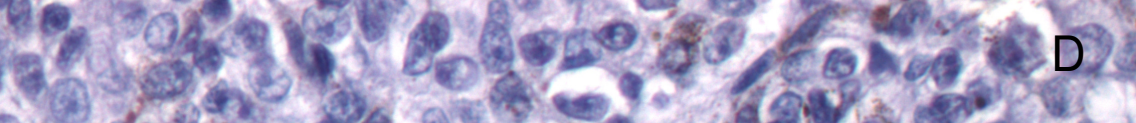

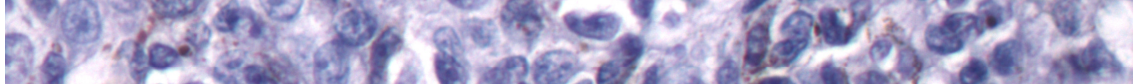

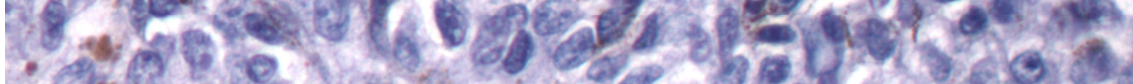

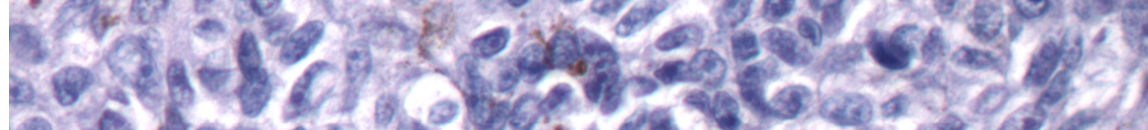

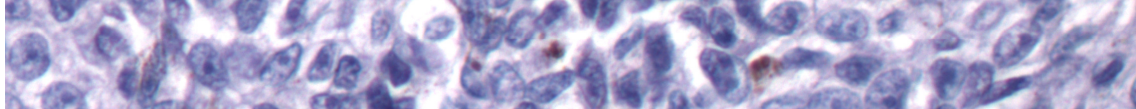

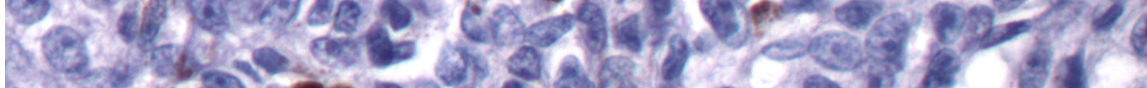

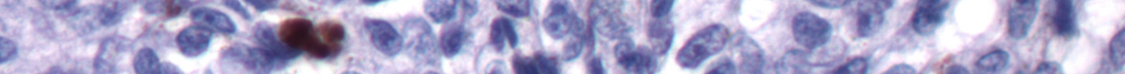

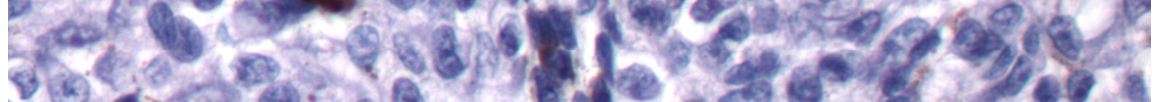

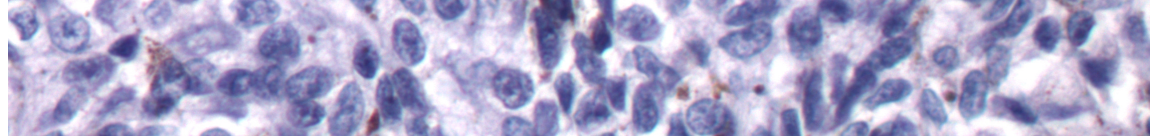

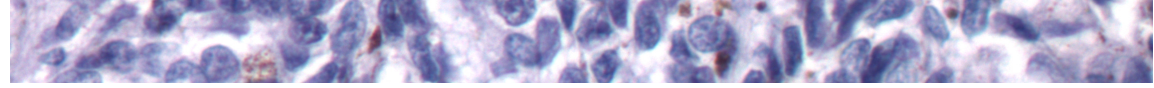




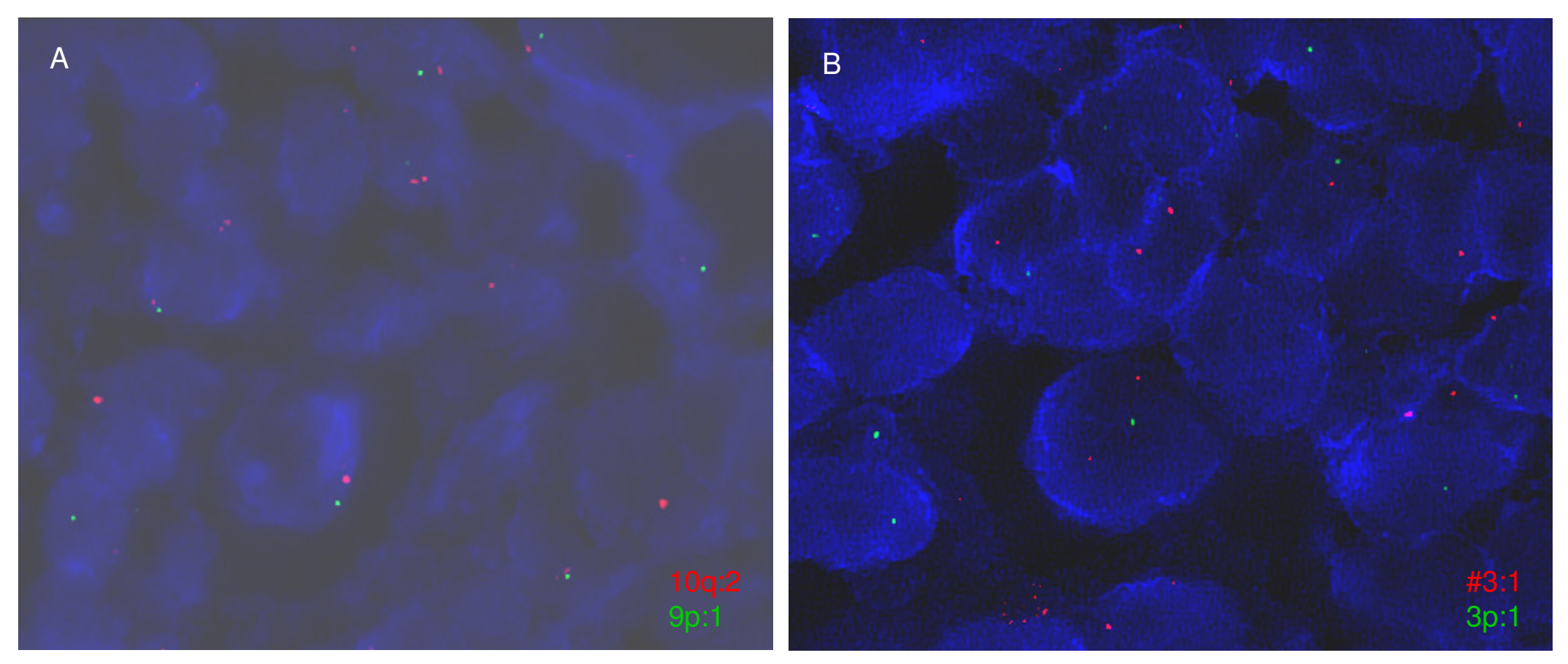

